Revista Digital Universitaria

Vol. 21, Núm. 4, julio-agosto 2020

\title{
De brujas y mujeres
}

Morgana Carranco

\section{Resumen}

Existe una asociación entre brujas y mujeres. Pero ¿cuál es la razón de ello? ¿Hay algún acontecimiento que lo justifique? En este artículo, mediante algunas consideraciones históricas, se trata de elucidar el vínculo entre estos dos conceptos.

Palabras clave: bruja, mujer, hechicera, caza de brujas, feminismo.

\section{OF WITCHES AND WOMEN}

\section{Abstract}

There is an association between witches and women. But what is the reason for it? Is there an event that justifies it? In this paper, through some historical considerations, we try to elucidate the connection between these two concepts.

Keywords: witch, woman, sorceress, witch hunt, feminism.

Dol: http://doi.org/10.22201/cuaieed.16076079e.2020.21.4.4 


\section{Morgana Carranco}

morgana.carranco@gmail.com

https://orcid.org/0000-0002-2520-2560

Estudió la Licenciatura en Ciencias Genómicas y la Licenciatura en Lengua y Literaturas Hispánicas, ambas en la Universidad Nacional Autónoma de México (UNAM). Actualmente cursa la Maestría en Letras (Letras Mexicanas) en la misma institución.

Tomó el III Diplomado "La literatura infantil y juvenil" de la unAm, el xII Diplomado en Creación Literaria del Centro de Creación Literaria Xavier Villaurrutia del Instituto Nacional de Bellas Artes (INBA) y el Diplomado en Traducción de Textos Especializados de la unAm. Asimismo, en 2017, fue seleccionada para participar en la Beca Juan Grijalbo, Seminario de Introducción al Mundo del Libro y la Revista, organizada por la Cámara Nacional de la Industria Editorial Mexicana (CANIEM).

Actualmente es editora técnica y correctora de estilo en la Revista Digital Universitaria, publicación de la unam para la comunicación social de las ciencias, las humanidades y las artes. Ha participado en la plataforma de divulgación Cienciorama y en la revista Pretextos literarios por escrito. Está interesada en la creación literaria, la divulgación de las ciencias y las humanidades, la traducción, la literatura fantástica y el estudio de la figura de la bruja; forma parte del Seminario de Literatura Fantástica Hispanoamericana de la unam. 
"Eres una Bruja por el hecho de ser mujer, indómita, airada, alegre e inmortal"

Robin Morgan

"A las numerosas brujas que he conocido en el movimiento feminista y a otras brujas cuyas historias me han acompañado

durante más de veinticinco años dejando [...] un deseo inagotable por contarlas, por hacer que se conozcan, por asegurar que no serán olvidadas"

Silvia Federici

\section{¿Son siempre mujeres las brujas?}

En varias ocasiones me he preguntado por qué existe la asociación entre brujas y mujeres. No es que no haya excepciones, pero cuando pensamos en una bruja casi siempre figuramos a una mujer. Cuando visualizamos a un hombre con magia, en cambio, se trata de un mago. Aún más, subsiste una connotación negativa hacia las brujas. ¿Cuál es la razón? ¿Hay algún acontecimiento histórico o alguna explicación lógica que lo fundamente? La respuesta no es sencilla. A pesar de toda la información al respecto (ver video 1) y de las múltiples explicaciones ofrecidas, no parece haber un argumento único que aclare dichos cuestionamientos. Por ello, es mi intención en este artículo explorar algunos de los motivos por los que se da dicho vínculo.

Video 1. El origen de las brujas (TikTak Draw, 2019).

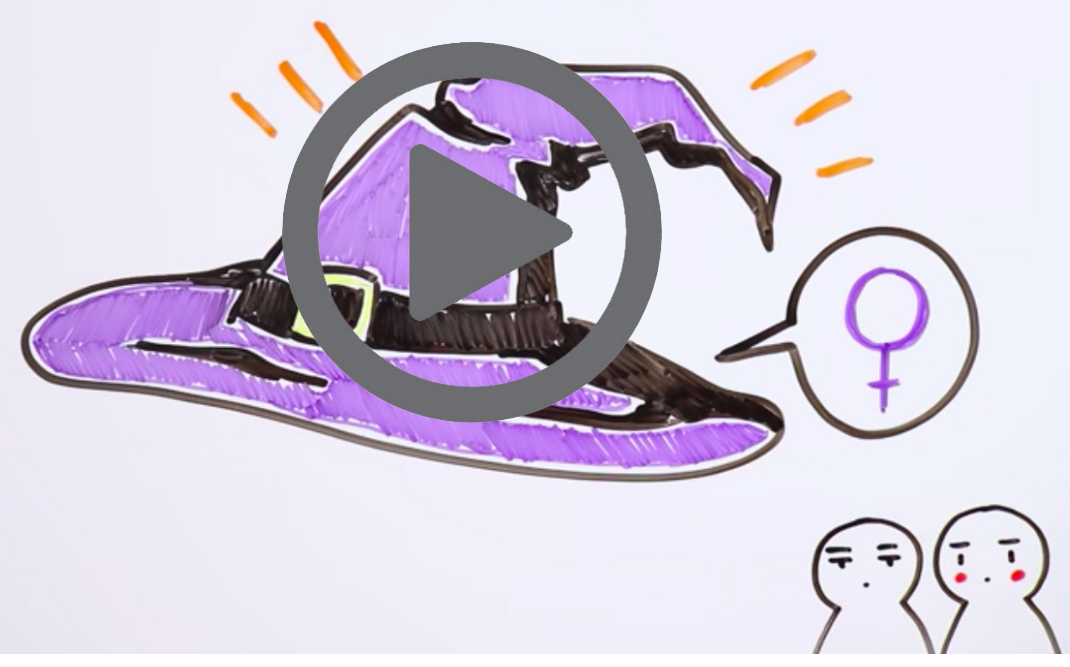




\section{La hechicera de la Antigüedad clásica}

Para que exista la figura de la bruja, debe de haber un sistema que la admita, ${ }^{1}$ una cosmogonía que la propicie. ${ }^{2}$ Así, el estudioso Julio Caro Baroja plantea que en la Antigüedad clásica, ${ }^{3}$ la magia y la religión están unidas, mediante la convergencia en su campo de acción. A pesar de que el pensamiento mágico opera en "el campo del deseo y de la voluntad [...] en tanto en cuanto la mente humana se somete de modo fundamental a ideas de acatamiento, agradecimiento y sumisión, sigue dentro del campo de los sentimientos religiosos" (2003, p. 49). ${ }^{4}$

De esta manera, en el mundo clásico, la magia benéfica no sólo era lícita, sino hasta imprescindible, pues había profesionales que se dedicaban a ella, como sacerdotes y médicos. Sin embargo, en un ámbito más cotidiano, cuando alguna persona tenía el deseo de alcanzar un objetivo, podía recurrir a medios más allá de los naturales para obtenerlo, mediante un mago o sacerdote, o una hechicera (Caro Baroja, 2003).

Imagen 1. Existe un vínculo entre lo femenino, el ciclo menstrual, la luna y la noche.

${ }^{1}$ En esto me baso en Julio Caro Baroja, en la metodología que utilizó para su libro Las brujas y su mundo. Él manifiesta que "para que se den la bruja, o la hechicera, o el mago (cada cual con sus atributos respectivos), tienen que existir unas estructuras particulares con arreglo a las cuales funciona la sociedad" (2002, pp. 20-21).

2 Para Caro Baroja debe de haber una particular "idea de lo real en el mundo habitado con la bruja, y aún más que esto, examinar lo que creen que es real aquellos que se consideran víctimas de ésta; porque se ha de advertir que la información que poseemos en punto a Hechicería, y sobre todo Brujería, es mucho más abundante del lado del que cree en brujas que del lado del que se cree a sí mismo brujo o bruja" (2003, pp. 18-19).

${ }^{3}$ Antigüedad clásica o mundo clásico se refiere a la Edad Antigua de las civilizaciones griega y romana.

${ }^{4} \mathrm{~A}$ menos que se indique lo contrario, todas las cursivas son originales.
La hechicería, en este contexto, sería la magia negra, en el sentido de que se asocia con la noche, con lo oculto, lo maléfico; a aquella se le opone la magia blanca, vinculada con el día, lo público, lo bueno (Caro Bajora, 2003, p. 52). Siendo así, también hay una relación - evidente- entre la noche y la luna, así como de ésta última con el ciclo menstrual y con la mujer. Llegamos, de este modo, a la primera razón por la que se da la asociación entre mujer y bruja, que tal vez haya "podido contribuir a que se establezcan otras más complicadas, a través de vías menos claras, subconscientes" (Caro Baroja, 2003, p. 33, ver imagen 1).




Es de esta manera cómo se une a la noche y a la luna con ciertas divinidades del inframundo como Diana, Selene o Hécate, que se vinculan, a su vez, con sus adeptas, Circe y Medea; y ellas con la figura de la hechicera. En consecuencia, en el mundo clásico, existe evidencia de la creencia en mujeres que realizaban hechizos, especialmente de amor, que eran alcahuetas, que invocaban fenómenos naturales o enfermedades, capaces de metamorfosearse, expertas en las hierbas, venenos y perfumes, y que se reunían bajo la protección de la noche para adorar a Hécate o Diana (Caro Baroja, 2003, 70-71). Así, desde la Antigüedad clásica, se observan las conexiones, a veces evidentes, otras no tanto, entre la mujer y la hechicera.

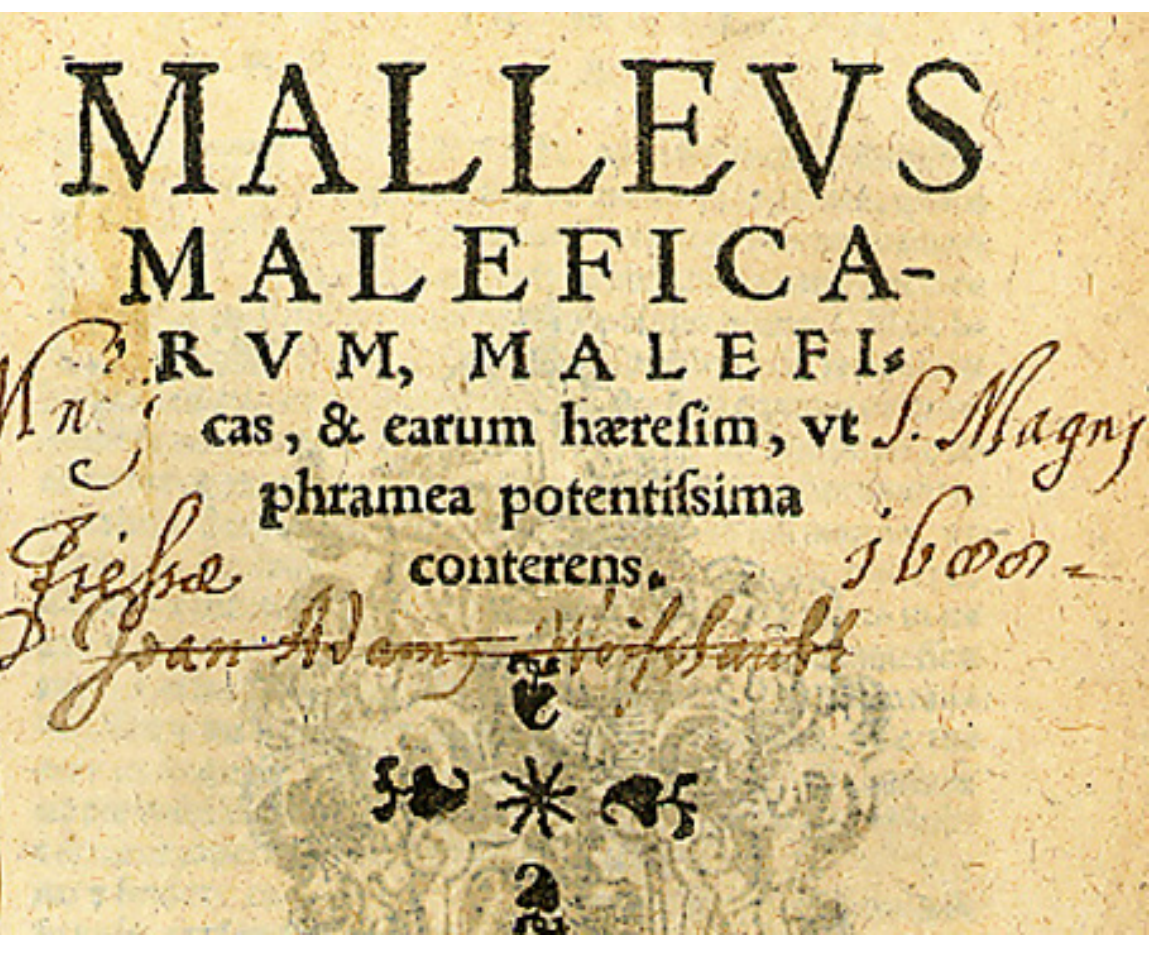

\section{De hechicera a bruja}

Los vínculos de las mujeres y de las hechiceras de la Antigüedad clásica se reestructuran entre finales del Medievo e inicios del Renacimiento, cuando las hechiceras se convierten en brujas. Hay dos eventos que consolidan el imaginario brujeril. El primero ocurre el 5 de diciembre de 1484, con la emisión de la bula Summis desiderantes affectibus. En ella, el papa de Inocencio vilI reconoce la existencia de las brujas y sus poderes, y las califica de amenaza.

El segundo evento que afianza la figura de la bruja fue la publicación, en 1487, del Malleus maleficarum, o El martillo de las brujas (ver imagen 2), atribuido a dos frailes dominicos: Heinrich Kramer y Jacob Sprenger. ${ }^{5}$ En dicho tratado, primero, se trata

Imagen 2. Portada de la séptima edición de Colonia de El martillo de las brujas, escrito en 1486 y publicado en 1487 (Malleus maleficarum, 1520).

La autoría de Sprenger ha sido cuestionada debido a su adición tardía y posterior a su muerte. Si se quiere saber más sobre el Malleus maleficarum se recomienda ver el documental $\underline{\underline{L a}}$ biblia de los cazadores de brujas. de convencer al lector de la existencia de las brujas, al hacer un breve recorrido de la historia, filosofía y teología de la brujería. Posteriormente, se delimitan sus características. Y, al final, se comparten los medios para descubrirlas y acabar con ellas. De esta manera, el concepto de bruja, a través de la publicación de dicho libro, se vuelve "netamente cristiano porque representa a la bruja como la imagen invertida del buen cristiano: adora al Diablo en lugar de a Dios" (Nathan Bravo, 1997, p. 22).

La hechicera se convierte en bruja al agregársele ciertos elementos. El primero, el sabbat o aquelarre, las asambleas de brujas en el campo, donde se burlan de los ritos cristianos, adoran al Demonio y se unen carnalmente con él y con otros de sus seguidores. Segundo, el pacto con el diablo (ver imagen 3). El sabbat es importante puesto que socializa, hace colectiva, la hechicería, que hasta entonces era mayoritariamente individual, además de que sustituye 
Imagen 3. El pacto con el Diablo es una característica que define a la bruja medieval-renacentista y a la bruja en general. Se parece mucho al pacto con el señor feudal, propio de la época (Smootz, 1608). el culto a Hécate o a Diana por el del Demonio. El pacto hace que la bruja deje de ser una hechicera, que pierda sus capacidades transmitidas de madre a hija y/o descubiertas y aprendidas por sí misma. Ya no es esa mujer que sabe cómo curar, que conoce las hierbas y sus propiedades, que puede atender los partos y la sexualidad femenina. Se convierte en una sirviente, una criada, del Diablo:

[...] se incorporó la idea teológica de que los males que ésta causaba se debían a la existencia de un pacto con el Diablo, o por el poder que éste les otorgaba. De acuerdo con lo anterior, era el ser maligno quien le enseñaba a la bruja qué fórmulas pronunciar, qué objetos utilizar y cómo manipularlos para producir los maleficios (Blázquez Graf, 2014, p. 32).



Así, "el concepto de hechicera pertenece a un conjunto de ideas mágicas que [...] se encuentran dispersas y con tenues relaciones entre sí. En cambio, el concepto de bruja remite a una demonología, a una teoría sistemática sobre el Diablo y las brujas, en la cual se establecen con precisión las relaciones entre sus modos de actuar, sus propósitos, etcétera" (Nathan Bravo, 1997, p. 23).

En consecuencia, el Malleus maleficarum desempeña dos funciones claves en la persecución de las brujas: por un lado, la sistematiza al definir qué se considera una bruja, por qué es peligrosa y cómo cazarla (ver video 2); y por otro, fija el vínculo entre mujeres y brujas. Al respecto, contiene un capítulo titulado "Acerca de las brujas que copulan con demonios. Por qué las mujeres son las principales adeptas a las malvadas supercherías", con dos secciones: "Por qué la 
Por un lado, las hechiceras desempeñaban diversas labores: parteras, nodrizas, curanderas, perfumistas, cocineras. Por ello, habían desarrollado ciertos conocimientos que les eran propios. Éstos, no obstante, "fueron considerados sospechosos y amenazantes, pues atentaban probablemente contra las instituciones nacientes del poder político, religioso y científico" (Blázquez Graf, 2008, p. 31).

De este modo, la académica Norma Blázquez Graf propone que "en los procesos de brujería no sólo se perseguía a la magia o a las mujeres sino a la magia de las mujeres, y que una de las principales razones para perseguirlas era una intolerancia a los conocimientos relacionados con la sexualidad y la vida que dominaban y practicaban desde épocas ancestrales, y que era necesario controlar" (2008, p. 30).

Por otro lado, es importante hacer notar que en la misma época de la caza de brujas se estaba instaurando el sistema capitalista. Por consiguiente, y de acuerdo con la evidencia de que la mayoría de acusadas y asesinadas fueron mujeres, la filósofa Silvia Federici plantea que la persecusión de brujas "fue un ataque a la resistencia que las mujeres opusieron a la difusión de las relaciones capitalistas y al poder que habían obtenido en virtud de su sexualidad, su control sobre la reproducción y su capacidad de curar" (2015, p. 281, ver video 3).

Video 3. La Caza de Brujas en Silvia Federici: Mujer, Sexualidad y Capitalismo (Quiltro, 2018).

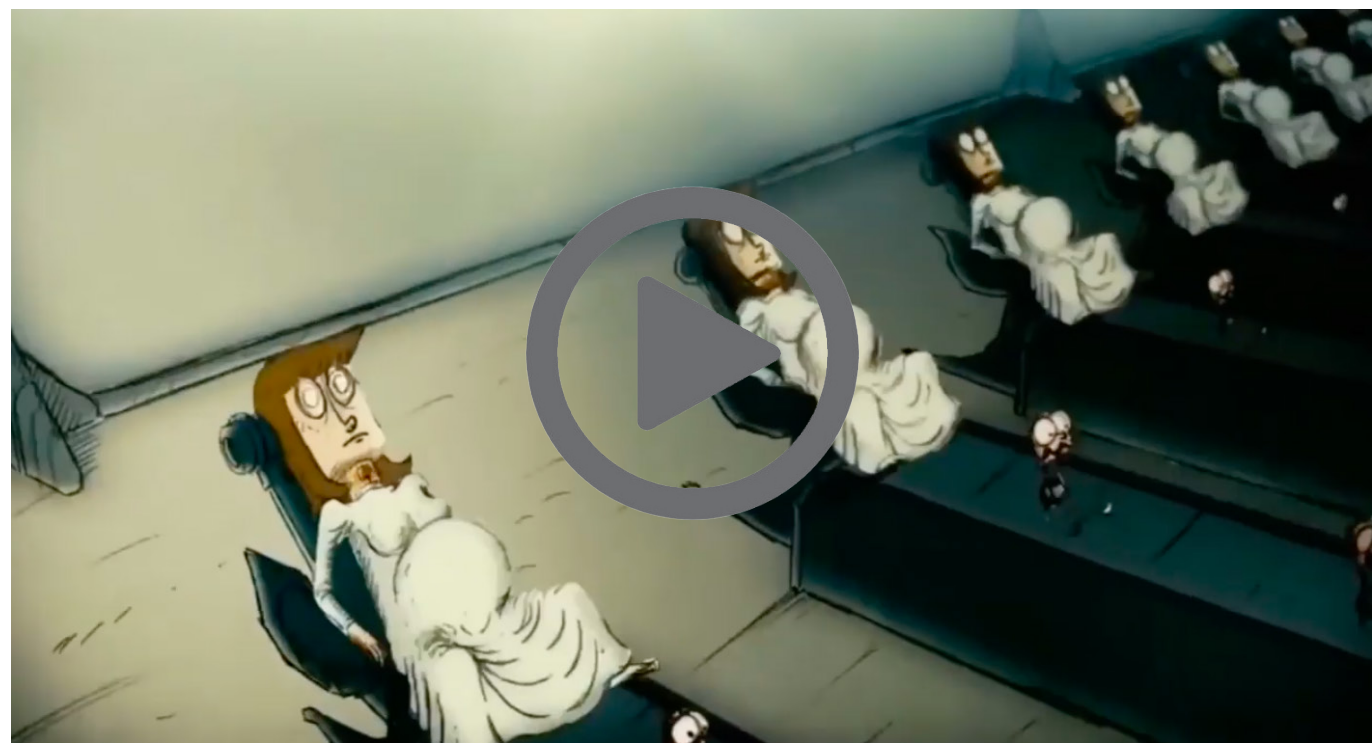

Asimismo, en su libro Calibán y la bruja: mujeres, cuerpo y acumulación originaria (ver video 4), Federici expone que se buscaba alcanzar el control sobre la sexualidad de la mujer porque los cuerpos de las mujeres tenían que estar "bajo el control del estado y [ser] transformados en recursos económicos" (2015, p. 281). De este modo, se prohibieron ciertos comportamientos y se apoyaron otros, y la mujer, mediante una sexualidad únicamente productiva, pasó a ser la generadora de la fuerza de trabajo que se necesitaba. 
Video 4. Silvia Federici habla sobre su libro Calibán y la bruja (Zur pueblodevoces, 2017).

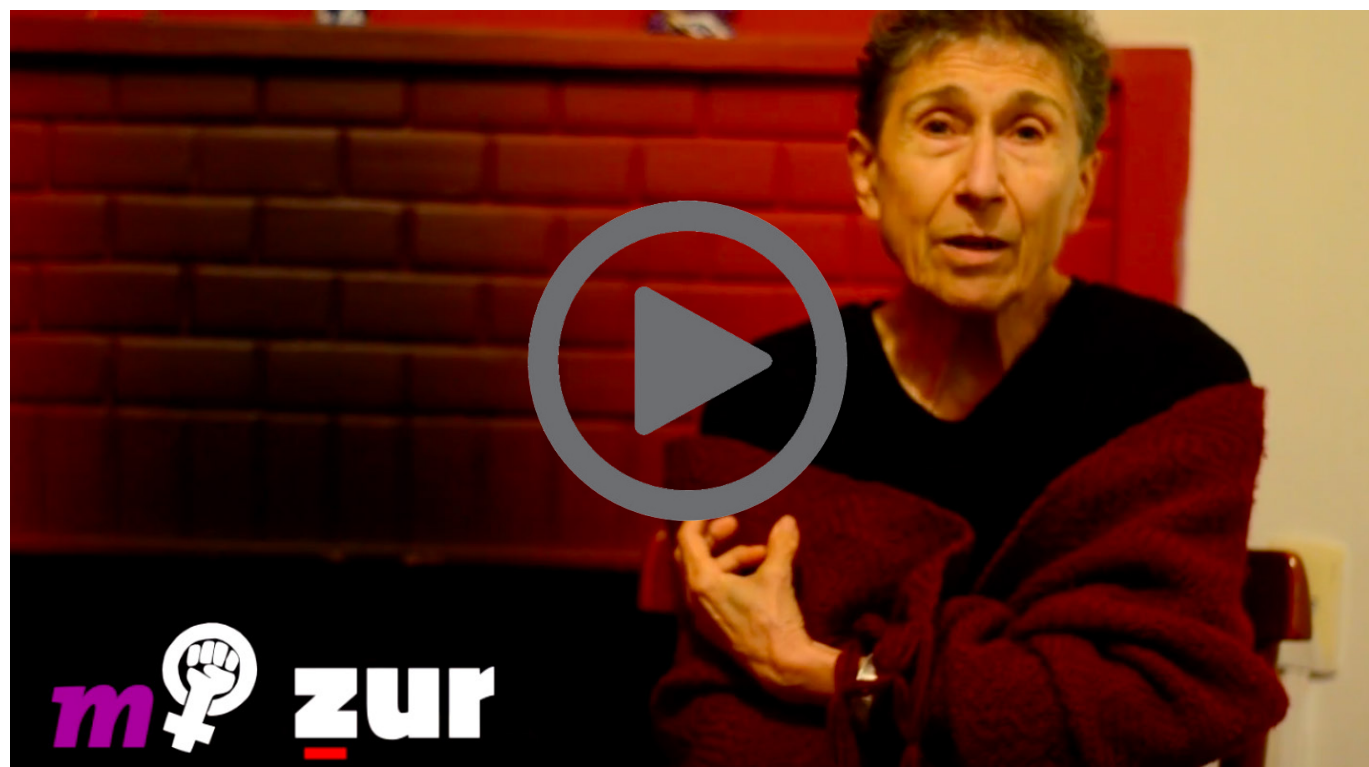

\section{¿Quién define a las brujas, a las mujeres?}

Hasta ahora nos hemos encontrado con concepciones de las brujas y las mujeres que han sido construidas por alguien más. Son las élites religiosas, los inquisidores con sus manuales, los juzgados civiles, los que toman la palabra para darles forma, para resaltar ciertos rasgos, ocultar y crear otros. Así, al no estar definidas por un discurso propio, se convierten en el enemigo, y por ello son siempre marginales y se les adjudica lo que la institución hegemónica considere conveniente. Las brujas, entonces, encarnan la otredad, lo que "hace de su posible discurso un discurso corrompido, atravesado por voces que no son la suya y que la sofocan" (Cohen, 2018, p. 33).

Las brujas empiezan a adueñarse de su voz hasta el siglo xx, cuando surgen asociaciones que conscientemente se adscriben a algunas características de las hechiceras o de las brujas medievales-renacentistas. Por un lado, ciertos individuos se reconocen brujos — destaco la inclusión de ambos sexos-, al considerar la brujería como "una suerte de religión pagana muy antigua, con cultos de fertilidad, invocaciones a los espíritus, uso de círculos mágicos, etcétera, y que, al igual que las religiones establecidas, ofrece un camino de salvación" (Nathan Bravo, 1997, p. 25). Aquí entran las congregaciones wiccas y otros caminos espirituales neopaganos. Por otro, también hay grupos satanistas que se identifican como brujos, y que "se caracterizan por adorar al Diablo" (Nathan Bravo, 1997, p. 25).

De la misma forma, distintas agrupaciones feministas han retomado el término bruja como bandera de su fuerza y poder. Harta de los abusos en su contra, la mujer torna a la colectividad para que un símbolo tan grandioso como el de la bruja las vincule y las acerque. Como ejemplo está "la creación de WiTcH 
Imagen 5. Integrantes de WITCH Boston, con carteles en oposición de las protestas contra la libertad de expresión de Boston el 19 de agosto de 2017 (GorillaWarfare, 2017). (bruja) [Women's International Terrorist Conspiracy from Hell], una red de grupos feministas autónomos que jugó un papel importante en la fase inicial del movimiento de liberación de las mujeres en Estados Unidos" (Federici, 2015, p. 267). Después, "el acrónimo inicial fue reformulado con otros significados, según la causa. Otro grupo que usó el mismo anagrama -Women Inspired To Commit Herstory - se inspiró en la retórica del crimen, identificando prácticas académicas como la lectura, la escritura y la enseñanza de la magia y la brujería como objetos de persecución" (Broad, 2014, p. 10, imagen 5).

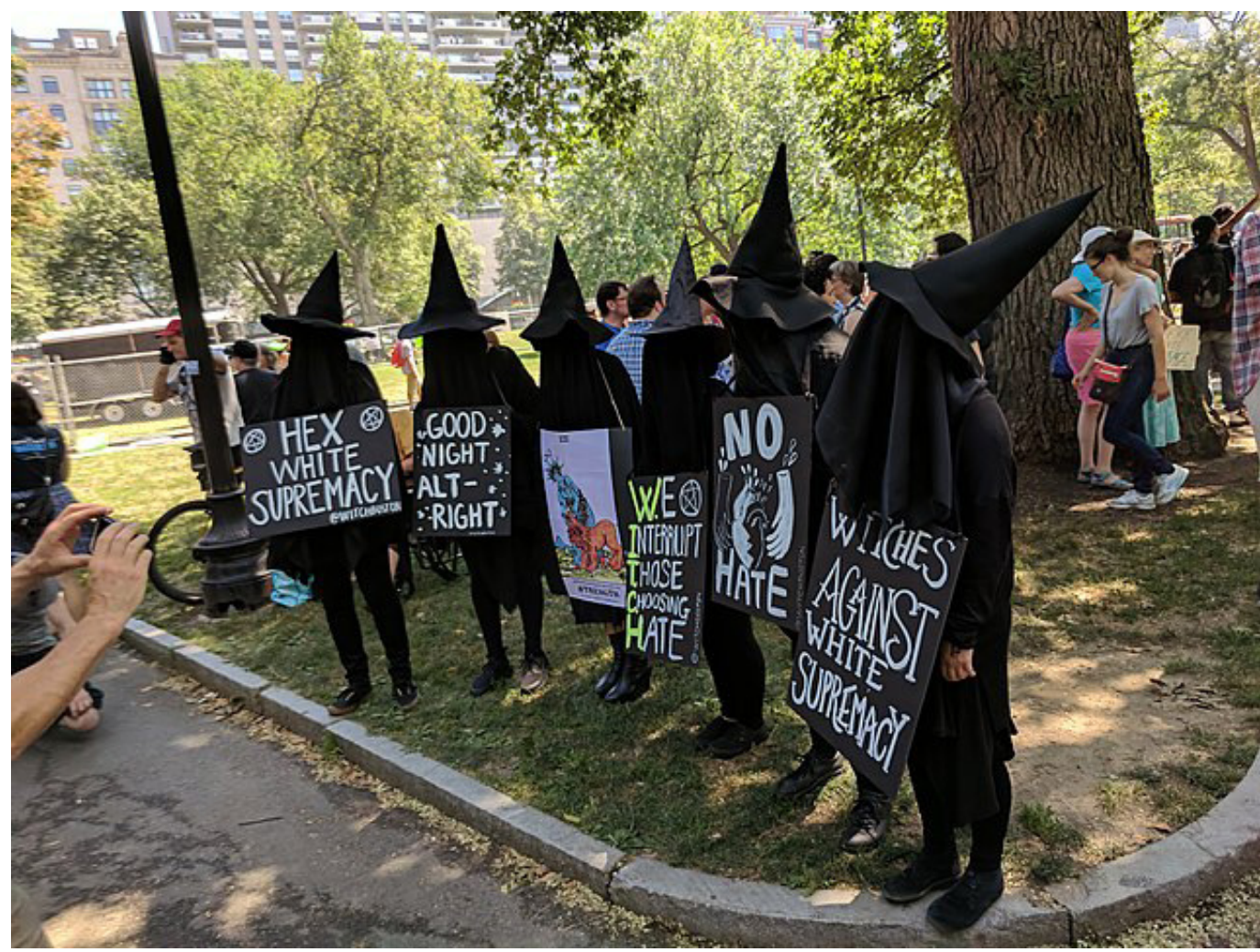

\section{Soy mujer, soy bruja}

La bruja, por muchos años, estuvo definida por quienes dominaban su entorno. Es hasta hace poco que la voz de la enunciación cambió, y la bruja se construyó a sí misma. Al dejar de ser el otro, al estar determinadas por ellas mismas, las asociaciones mencionadas pueden elegir los atributos que prefieran, tomar el símbolo de la bruja y resignificarla. Ahora, la voz que define a la bruja proviene de ella misma, no está controlada por alguien más; y, al colocarse en el centro, se construye a sí misma, ya no silenciada o invisible, si no como un ente que ostenta el poder, que sabe cómo usarlo y que va a hacerlo.

Efectivamente, como lo asienta Robin Morgan, una de las feministas y activistas cofundadoras del primer WITCH: 
Imagen 6. Muchas mujeres hoy en día se consideran a sí mismas como brujas. Así, la bruja se ha convertido en un símbolo de fuerza y de lucha.
Las brujas siempre han sido mujeres que se atrevieron a ser valerosas, agresivas, inteligentes, no conformistas, curiosas, independientes, liberadas sexualmente, revolucionarias [...] WITCH vive y ríe en cada mujer. Ella es la parte libre de cada una de nosotras [...] Eres una Bruja por el hecho de ser mujer, indómita, airada, alegre e inmortal (cit. en Federici, 2015, p. 267, ver imagen 6).

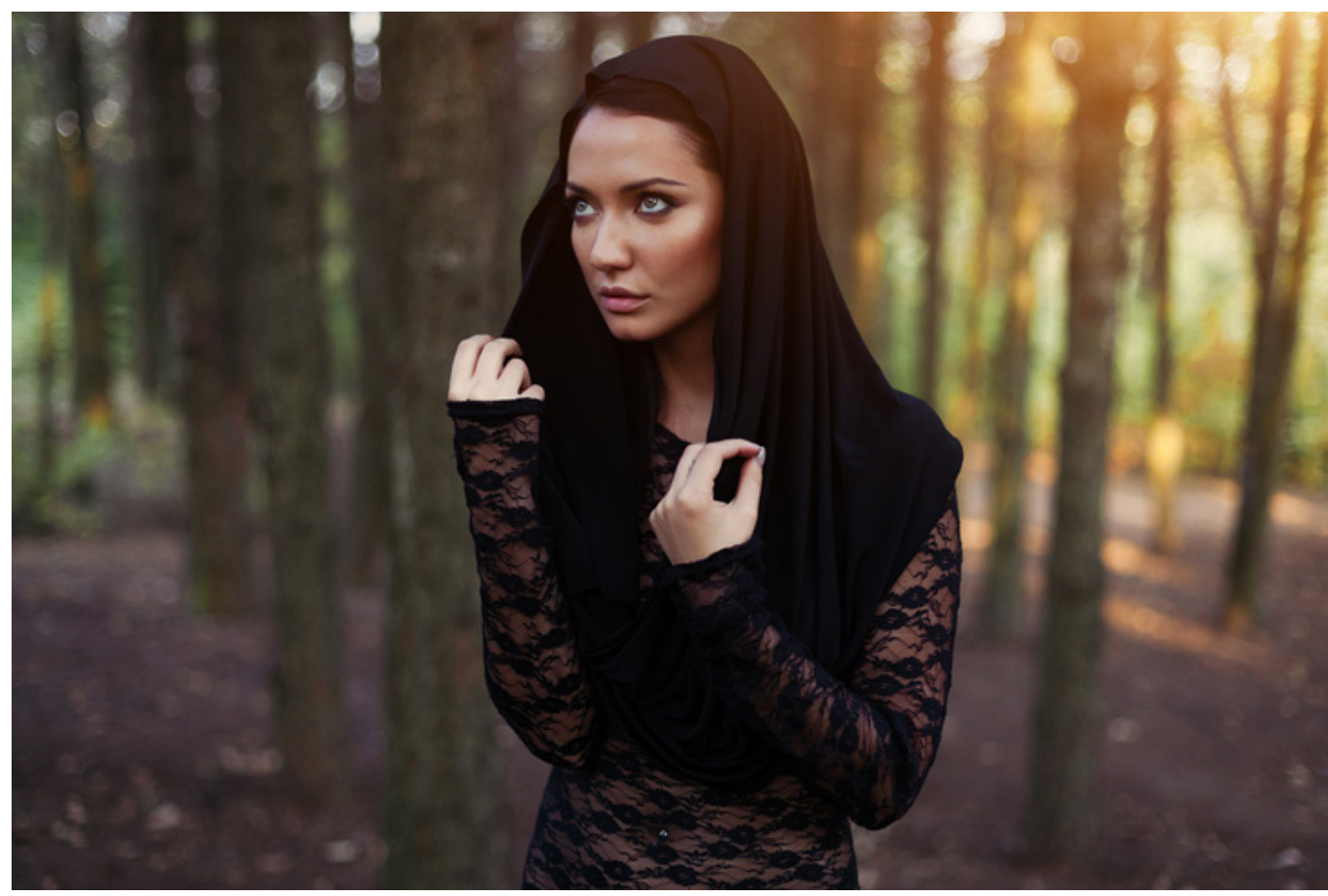

Es por ello que muchas mujeres en la actualidad se consideran brujas, porque son herederas de las injusticias que sufrieron sus antecesoras históricas y que hoy en día seguimos viviendo las mujeres. Porque son independientes, porque no están dispuestas a supeditarse al patriarcado, porque con su actitud y su forma de ver el mundo desestabilizan la estructuras hegemónicas, porque asumen y promueven el derecho de elegir sobre sexualidad y su cuerpo, porque se interpretan y se definen a sí mismas. Este tipo de brujas ya se ha resignificado y se transfigura y autodefine cada día. Y esta bruja busca generar un cambio en la concepción del mundo, la cual, por muchos años, la determinó a ella.

\section{Referencias}

- Blazquez Graf, N. (2008). El retorno de las brujas: Incorporación, aportaciones y críticas de las mujeres en la ciencia. Universidad Nacional Autónoma de México, Centro de Investigaciones Interdisciplinarias en Ciencias y Humanidades.

- Blázquez Graf, N. (2014). Los conocimientos de las brujas: Causa de su persecución. En M. Fe (Ed.), Mujeres en la hoguera: Representaciones culturales y literarias de la figura de la bruja (pp. 31-39). Universidad Nacional Autónoma de México. 
* Broad, C. (2014). Introducción. En M. Fe (Coord.), Mujeres en la hoguera: Representaciones culturales y literarias de la figura de la bruja (pp. 7-15). Universidad Nacional Autónoma de México.

* Caro Baroja, J. (2003). Las brujas y su mundo. Alianza Editorial. (Publicado originalmente en 1961).

* Cohen, E. (2018). Con el diablo en el cuerpo: Filósofos y brujas en el Renacimiento. Universidad Nacional Autónoma de México.

* Federici, S. (2015). Calibán y la bruja: Mujeres, cuerpo y acumulación originaria (V. Hendel y L. S. Touza, Trads.). Tinta Limón Ediciones. (Publicado originalmente en 2004).

- GorillaWarfare. (2017, 19 de agosto). W.I.T.C.H. Boston counterprotesters at the Boston Free Speech rally [fotografía]. https://en.wikipedia.org/wiki/File:W.I.T.C.H. Boston counterprotesters at the Boston Free Speech rally.jpg

- Kramer, H., y Sprenger, J. (2016). Malleus maleficarum. El martillo de los brujos. Distribuidora Editorial Más Libros. (Publicado originalmente en 1487).

* Malleus maleficarum [portada de la séptima edición de Colonia]. (1520). https:// en.wikipedia.org/wiki/File:Malleus.jpg

* Nathan Bravo, E. (1997). Territorios del mal: Un estudio sobre la persecución europea de Brujas. Universidad Nacional Autónoma de México.

* Quiltro. (2018, 11 de septiembre). La Caza de Brujas en Silvia Federici: Mujer, Sexualidad y Capitalismo [video]. YouTube. https://youtu.be/FRUvKXhD36E

* Smootz, D. (1608). CompendiumMaleficarumEngraving5 [grabado de madera 5 del Compendium Maleficarum]. https://commons.wikimedia.org/wiki/File:Compen diumMaleficarumEngraving5.jpg

* Supercurioso. (2017, 9 de marzo). 8 Rasgos por los que antiguamente serías BRUJA [video]. YouTube. https://youtu.be/Ut]GvyHk2CM

* TikTak Draw. (2019, 23 de octubre). EL ORIGEN DE LAS BRUJAS | Draw My Life [video]. YouTube. https://youtu.be/HxadwVn7Kkl

* Wick, J. J. (1585, 4 de noviembre). Wickiana5 [ejecución de tres brujas en Baden, Suiza, ilustración de Wickiana]. https://commons.wikimedia.org/wiki/ File:Wickiana5.jpg

* Zur pueblodevoces. (2017, 26 de julio). Calibán y la bruja [video]. YouTube. https:// youtu.be/GdijSEwAHz8

\section{Cómo citar este artículo}

* Carranco, Morgana. (2020, julio-agosto). De brujas y mujeres. Revista Digital Universitaria (RDU), 21(4). Dol: http://doi.org/10.22201/codeic.16076079e.2020.21.4.4

Recepción: 17/05/2020. Aceptación: 29/05/2020 